\title{
Venice is Disneyland. Gentrificacion del patrimonio cultural en la sociedad globalizada actual
}

\author{
Patricia Alonso Arroba | grupo de investigacion HUM-1025 Creación, arte gráfico y género, Universidad de Sevilla \\ URL de la contribución <www.iaph.es/revistaph/index.php/revistaph/article/view/4491>
}

Recientemente volvió a ser titular en los medios de comunicación a nivel internacional y en las redes sociales el desafortunado suceso en el cual una nave de crucero perdió el control por culpa del mal tiempo y estuvo a punto de chocar contra el muelle en Riva degli Schiavoni en Venecia ${ }^{1}$. El 2 de junio había ocurrido algo similar mientras otro crucero conducía su paso por el canal de la Giudecca, sin factores externos, como las condiciones meteorológicas, que pudiesen justificarlo.

Este tipo de acontecimientos, que se han producido últimamente en la ciudad de Venecia, ha tenido gran repercusión mediática ya que se trata de una ciudad de destino vacacional mundialmente conocida. Los sucesos replantean el problema de la gentrificación y turistificación y de cómo estamos gestionando nuestras comunidades sin pensar en las consecuencias que estas políticas no reguladas supondrán para el futuro.

Se ha implantado un modelo de ciudad capitalista donde la economía se sustenta no en la producción en sí misma sino en el sector terciario del turismo. En este tipo de modelo de ciudad donde conviven residentes y visitantes no están regulados ciertos criterios de convivencia y sostenibilidad lo cual crea un cambio del prototipo de ciudad y de sus valores. Los servicios que en teoría deberían cubrir las necesidades de sus habitantes, como por ejemplo sanidad, educación, presencia de servicios básicos como supermercados, entidades publicas, etc. deberían estar garantizados. No obstante cuando los responsables de ofrecer una alternativa sostenible a este tipo de situaciones prefieren anteponer e incentivar el sector turístico por cuestiones económicas en lugar de las políticas sociales comienza la degradación y el principio del fin de la ciudad, ya sea desde el punto de vista cultural o social.
Este tipo de procesos destruyen la comunidad porque los pocos residentes, invadidos por una población temporal que obstruye su desarrollo a nivel profesional y vital si no se dedican al sector terciario, deciden emigrar hacia otras poblaciones en las cuales puedan encontrar los servicios primarios que les garanticen una vida adaptada a sus necesidades (alquileres más asequibles, servicios básicos garantizados, etc.). Este hecho implica una serie de factores muy importantes desde el punto de vista cultural: la disminución de la identidad y los valores de la ciudad en la que habitaba la comunidad; la pérdida de la tradición y cultura histórica de dichos lugares a favor de la globalización total de los lugares culturales. El patrimonio cultural sigue presente físicamente pero sin los valores que la comunidad no turística puede aportar.

Si ponemos como ejemplo Venecia, también podría ser Barcelona o Palma de Mallorca, ciudades donde el turismo invade las comunidades permanentes y el proceso de gentrificación llega a exponentes tan altos de degradación que las perspectivas para la supervivencia de dichas ciudades ha puesto en alerta incluso a la Unesco. Si en el pasado existían corrientes migratorias vinculadas a los periodos vacacionales, el presente estado de globalización en el cual vivimos condiciona y promueve una circulación planetaria durante todo el año.

En el caso específico de Venecia, la isla se está transformando en una ciudad fantasma debido a una subida de los alquileres desproporcionada para residentes, trabajos dedicados casi exclusivamente al sector terciario e ineficiente número de servicios que ofrece la ciudad que no son suficientes debido a la pequeña cantidad de habitantes que resisten en estas circunstancias. Un 

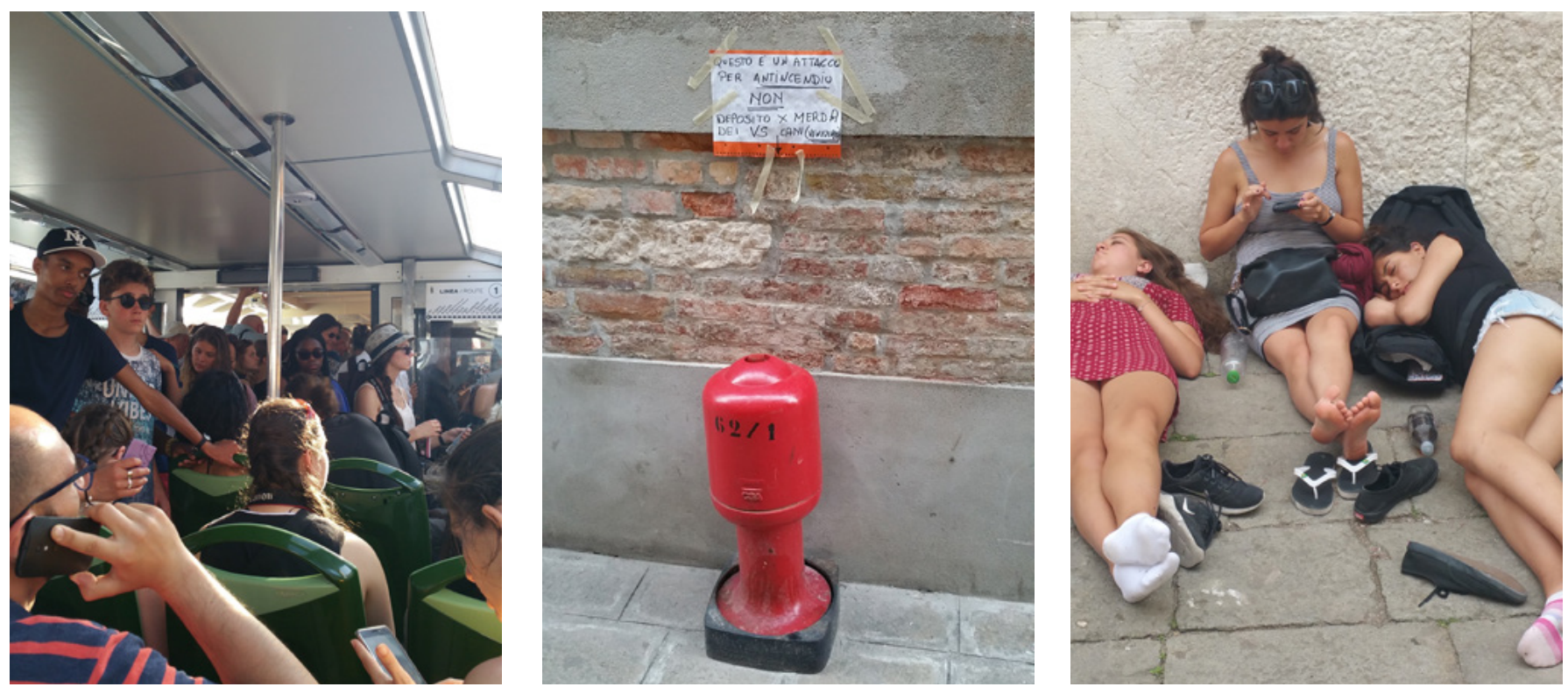

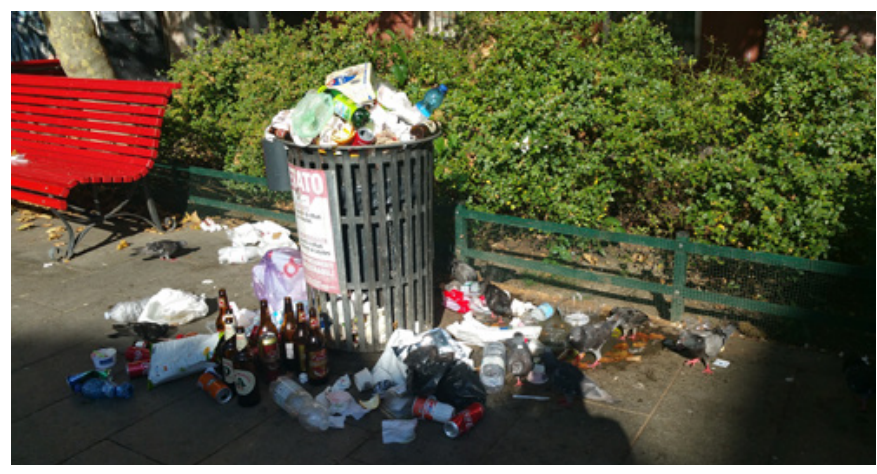

Escenas que denuncian los procesos de gentrificación y turistificación en Venecia

ejemplo es la problemática de los sistemas de transporte saturados por hordas de turistas que atrae este destino mundialmente conocido o simplemente la recogida de residuos diaria. El número de residentes censado en la ciudad se sitúa en 45.000 (hace 10 años eran 100.000), no obstante la cantidad de personas que a diario puede llegar en alta temporada, en la totalidad de la isla, es 300.000 .

Algunos grupos y colectivos locales ${ }^{2}$ intentan reivindicar sus derechos y la importancia de salvaguardar la ciudad para que su identidad no desaparezca. No obs-

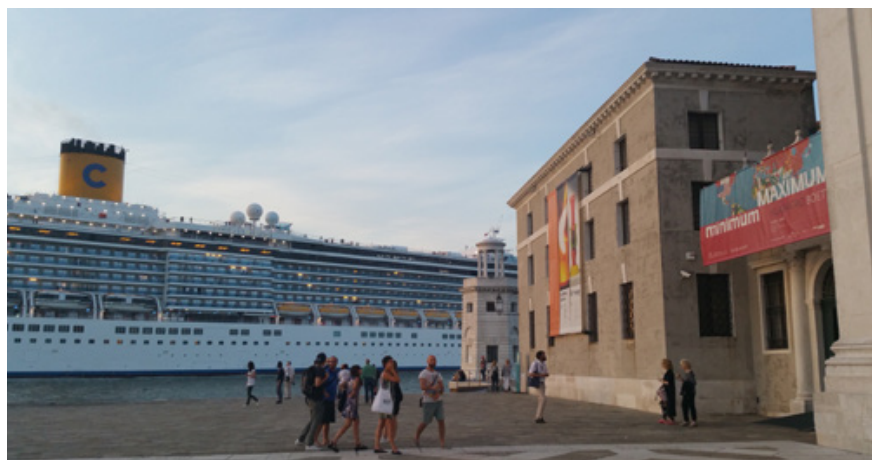

Masificación turística y sus consecuencias en los transportes, espacios y mobiliario público. Venecia, 2018-2019 | fotos Patricia Alonso Arroba

tante, al tratarse de pequeñas comunidades, los resultados obtenidos no son los deseados debido a las políticas adoptadas por las entidades competentes. Otras asociaciones internacionales ${ }^{3}$ recaudan fondos para restaurar y mantener el patrimonio histórico de la ciudad que no fue concebido en su día ni para el ingreso de cruceros ni a la cantidad de personas que visitan la ciudad cada año. Como dice John Berendt en su libro La ciudad de los ángeles caídos (2007: 2) "Cuidado: caen ángeles. Cartel colocado frente a la iglesia de Santa Maria della Salute a principios de la década de 1970, antes de la restauración de sus ornamentos de mármol". 


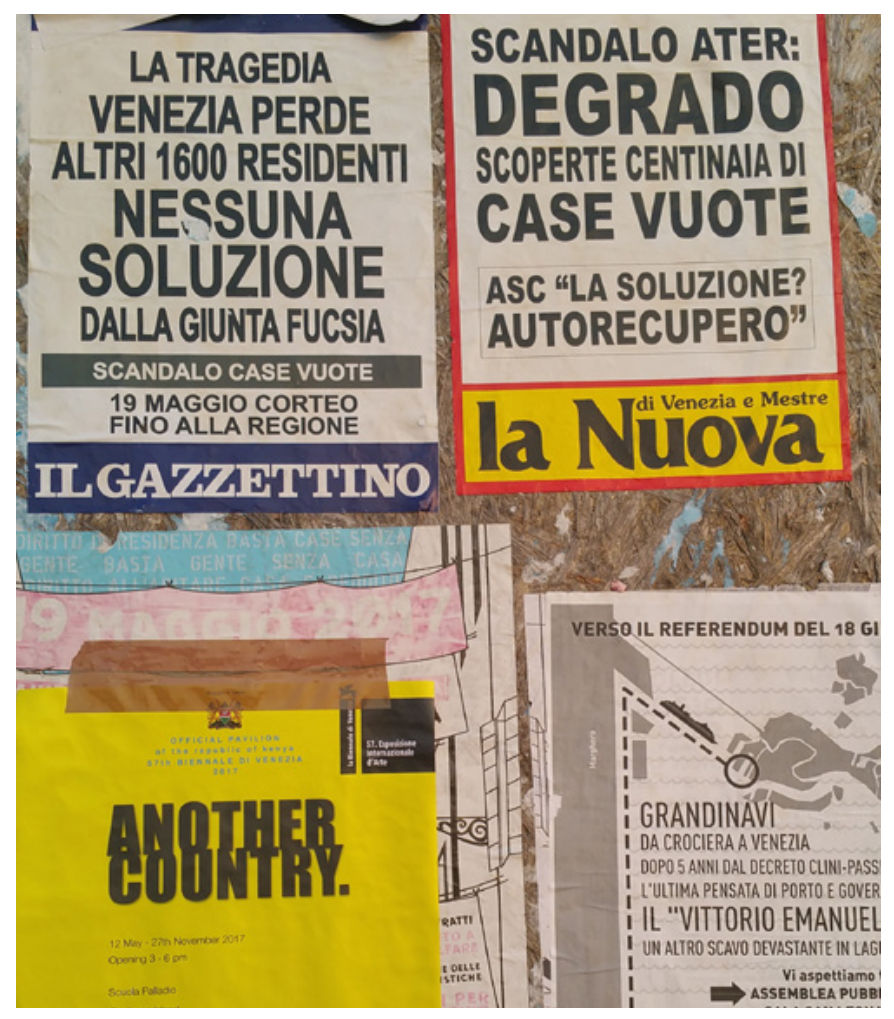

Carteles publicitarios de prensa local en las calles de Venecia. 2017 | foto Patricia Alonso Arroba

Por otro lado si hablamos de la importancia del llamado turismo cultural, existe una gran cantidad de museos, galerías, teatros o eventos (en el caso de Venecia, por ejemplo, la Bienal de Arte y Arquitectura ${ }^{4}$ ) que venden ya de por sí una marca de ciudad y atraen a una inmensa cantidad de turistas. Asimismo lo hacen las franquicias de comida rápida o moda que componen una visión de dichas ciudades no como centros patrimoniales sino como souvenirs sin contenido que poder mostrar en las redes sociales. Este tipo de comportamientos, cada vez más extenso, provoca una falta de interés real por el patrimonio cultural de las ciudades $y$, al mismo tiempo, no representa el espíritu y la historia de dichos lugares.

En definitiva se podría concluir con una breve reflexión, extensiva a todos y cada uno de nosotros, porque vivimos en comunidad en cualquier parte del mundo: el futuro de las comunidades, su entorno, su patrimonio cul- tural y su historia deberían estar protegidos y tutelados. Si no modificamos las políticas que regullen esa protección, perderemos no solo esos valores sino los aspectos más importantes que emergen de ellos: la identidad, nuestra identidad.

\section{NOTAS}

1. "Un crucero pierde el control en plena tormenta en Venecia" <https://elpais.com/elpais/2019/07/08/videos/1562607970_594588.html>; "Cruise Ship Rams Into Tourist Boat and Dock in Venice, Injuring at Least 4" <https://www.nytimes.com/2019/06/02/world/europe/ venice-cruise-ship-crash.html> [Consultas: 27/08/2019]

2. Una de las comunidades mas influyentes es el grupo 25 Aprile, una plataforma civica y vecinal cuyo objetivo es salvaguardar el ecosistema fragil de la laguna y la isla de Venecia promoviendo los derechos de los residentes de la ciudad y el respeto por la misma. Una de las iniciativas mas importantes es el llamado "No alle Grandi Navi", contra el paso de cruceros por el Bacino (cuenca hidrografica) de San Marcos <https://gruppo25aprile. org/> [Consultas: 27/08/2019]

3. Entre las asociaciones internacionales involucradas en salvaguardar el patrimonio cultural y artístico de Venecia se encuentra Save Venice <https://www.savevenice.org/> [Consultas: 27/08/2019]

4. En 2017 pude colaborar con el Proyecto Ciutat de Vacances, que se llevó a cabo durante la Bienal de Venecia; un proyecto de investigación y producción artística donde diferentes artistas cuestionaban el presente y el futuro de la problemática del tema que aquí nos atañe.

\section{BIBLIOGRAFÍA}

- BERENDT, J. La ciudad de los ángeles caídos. Barcelona: Editorial Debolsillo, 2007 